\title{
Assessment of the Water-Following Capabilities of CODE Drifters Based on Direct Relative Flow Measurements
}

\author{
PierRe-MARIE Poulain AND RicCARdo GERIN \\ Istituto Nazionale di Oceanografia e di Geofisica Sperimentale, Trieste, Italy
}

(Manuscript received 8 June 2018, in final form 28 December 2018)

\begin{abstract}
Direct measurements of the relative water flow near the top and bottom of Coastal Ocean Dynamics Experiment (CODE) drifters were made in the northeast Pacific Ocean and the Mediterranean Sea in wind speeds as large as $15 \mathrm{~m} \mathrm{~s}^{-1}$. These measurements confirmed that the CODE drifter is a good Lagrangian drifter with a mean downwind slip of about $0.1 \%$ of the wind speed. Substantial mean vertical shears across the drifter (top $1 \mathrm{~m}$ below the surface) were observed, reaching an amplitude of $12 \mathrm{~cm} \mathrm{~s}^{-1}$ and corresponding to strong stratification (due to the proximity of river runoff) and strong winds.
\end{abstract}

\section{Introduction}

Satellite-tracked drifters have been used since the 1980s to measure currents and water properties near the sea surface. They have been deployed in the global ocean basins and marine coastal areas as part of the Global Drifter Program (GDP; Niiler 2001; Lumpkin and Pazos 2007; Lumpkin et al. 2017) and various scientific projects. Their trajectory data have been exploited to study the kinematics and dynamics of the surface currents, from the large basin scale to inertial/tidal motions, including the mapping of the mean ocean circulation and seasonal/ mesoscale variability (Maximenko et al. 2013; Lumpkin and Johnson 2013) and the study of surface tidal currents (Poulain 2013; Poulain and Centurioni 2015; Poulain et al. 2018). Drifter programs in coastal environments and in marginal seas have also been conducted in various regions, such as the Gulf of Mexico (Ohlmann and Niiler 2005) and the Mediterranean Sea (Poulain et al. 2012, 2013). In addition, surface drifters have been used to calibrate and validate the surface currents measured by coastal high-frequency (Ohlmann et al. 2007; Molcard et al. 2009; Kalampokis et al. 2016) and X-band (Lund et al. 2018) radars and simulated by numerical ocean circulation models (Thoppil et al. 2011). Besides their use in oceanographic and climate research, drifters are also routinely used for search-and-rescue and oil spill tracking operations

Corresponding author: Dr. Pierre-Marie Poulain, ppoulain@ inogs.it
(Breivik et al. 2013) and to improve weather forecasting (Centurioni et al. 2017).

Surface drifters do not exactly follow the surface or near-surface horizontal currents at time scales longer than the surface gravity wave periods (e.g., longer than $1 \mathrm{~min}$ ) because 1) their relative motion with respect to the $3 \mathrm{D}$ flow associated with waves might be rectified into a net force, 2) the existence of strong shear of the horizontal currents near the surface, and 3) they must be partially in the air for tracking and data telemetry to the satellites; hence, they are inevitably directly affected by surface winds. As a result, drifters are not perfect Lagrangian instruments, and their ability to measure the currents is a major concern. Since the pioneering work of Kirwan et al. (1975), the effects of winds, waves, and surface currents on drifter systems have been studied extensively. For instance, the detailed behavior of Lagrangian drifters was studied experimentally (Niiler et al. 1987, 1995; Geyer 1989; Mackas et al. 1989) and numerically (Chereskin et al. 1989) for the Surface Velocity Program (SVP) drifter, a design commonly used to measure the surface mixed layer currents (at a nominal depth of $15 \mathrm{~m}$ ) in the open ocean. Using mechanical current meters attached to the SVP drifter Niiler et al. $(1987,1995)$ measured a relative flow ranging from 0.5 to $3.5 \mathrm{~cm} \mathrm{~s}^{-1}$. The most important parameters related to this slip were the ratio of the drag area of the drogue to the sum of the drag areas of the tether and surface floats $(R)$, the wind speed and direction, and the velocity difference between the top and bottom of the drogue (related to vertical shear). It was shown that for $R=40$, the 
relative slip of the SVP drifter is about $0.1 \%$ of the wind speed. More recently, the water-following characteristics of a new drifter design, the Consortium for Advanced Research on Transport of Hydrocarbon in the Environment (CARTHE) drifter were assessed both in the laboratory and at sea under a wide range of wave and wind conditions (Novelli et al. 2017). It was found that this drifter measures the currents in the top $60 \mathrm{~cm}$ below the sea surface with a wind-induced slip less than $0.5 \%$ of the wind speed and with minimum wave rectification effects.

The Coastal Ocean Dynamics Experiment (CODE) drifter was developed by Davis (1985) to measure the currents in the top meter of the water column in coastal areas. It consists of a vertical, 1-m-long negatively buoyant tube with four drag-producing vanes extending radially from the tube over its entire length and four small spherical surface floats attached to the upper extremities of the vanes to provide buoyancy (Poulain 1999). The water-following characteristics of the CODE were originally studied by Davis (1985). A test in a wave tank revealed that slippage due to surface wave rectification is less than $1.5 \mathrm{~cm} \mathrm{~s}^{-1}$, with a typical shear over the depth of the drag vanes of $2-5 \mathrm{~cm} \mathrm{~s}^{-1}$. The CODE slippage was roughly estimated at sea by comparing its velocity with those of nearby moored current meters. Davis (1985) concluded that CODE drifters are accurate to about $3 \mathrm{~cm} \mathrm{~s}^{-1}$, even under strong wind conditions. More recently, the response of wave and wind forcing on CODE drifters was studied by Röhrs et al. (2012) and Röhrs and Christensen (2015) but the slip of the drifter with respect to the currents was not specifically addressed.

Since the original work of Davis (1985) no detailed study of the water-following capabilities of the CODE drifter has been performed, despite the conspicuous and continuous use of this drifter design for scientific and operational applications. This motivated new experimental studies to assess the slippage of the CODE drifters by measuring directly the relative flow around the instrument while drifting at sea. The experiments were conducted between 2000 and 2002 in the northeast Pacific Ocean and in the Mediterranean Sea, in various wind and wave conditions, involving direct measurements of relative flow by means of acoustic Doppler velocimeters mounted on a prototype CODE drifter. The main goal of this paper is to report the results of these experiments. It is organized as follows. A brief background on the effects of wind and waves on surface drifters is given in section 2 . The technical specifications of the CODE drifter equipped with current meters are described in section 3. The measurements of relative flows and the ancillary data of wind and waves are also described. The results of the linear regression models applied to the data to estimate the wind-induced slippage of CODE drifters in various wind conditions are reported in section 4. These results are discussed and conclusions are made in the last section.

\section{Theoretical background}

Four principal physical aspects determine the effects of wind and waves on the motion of surface drifters at scales longer than the wave periods. First, there is the drag by the near-surface currents, including the winddriven Ekman currents (Ekman 1905) that rotate and decrease exponentially in the water column over the vertical extent of the drifter (roughly the top meter for the CODE). Second, being a quasi-Lagrangian instrument, the drifter is advected horizontally by the wave-induced Stokes drift, which decreases exponentially with depth (Stokes 1847; Breivik et al. 2014, 2016; Clarke and Van Gorder 2018). Both Ekman and Stokes drift currents create a vertical shear over the drifter vertical extent. Third, the highfrequency motion of the surface waves can be rectified into a net force on the drifter. Fourth, there is the direct drag action of the wind on the top elements of the drifters. All these elements produce a relative motion of the drifter with respect to the water at depth $z$ called "slip" $\mathbf{S}(z)$ defined as

$$
\mathbf{S}(z)=\mathbf{U}_{D}-\mathbf{U}_{E}(z)-\mathbf{U}_{S}(z),
$$

where $\mathbf{U}_{E}(z), \mathbf{U}_{S}(z)$, and $\mathbf{U}_{D}$ are $2 \mathrm{D}$ vectors representing the near-surface Eulerian currents, the Stokes drift velocities, and the drifter horizontal velocity, respectively. The near-surface Eulerian velocity, that is, the velocity measured by current meters or ADCPs on moorings or those simulated by Eulerian numerical models, includes the wind-driven Ekman currents.

Let us assume that the winds, waves, and currents are steady and that the quadratic drag law can be applied with constant drag coefficients. In this case, $\mathbf{U}_{D}$ is also steady. For the scales of motion and typical speeds of the drifter, we can also assume that the Coriolis force acting on it is negligible. Assuming no vertical dependence of the wind velocity over the vertical extent of the drifter element in the air, negligible stratification over the vertical length of the drifter $Z$, a drag coefficient independent of depth and no wave rectification effects, the equilibrium of forces acting on the drifter reduces to the balance between the underwater current drag and the wind drag on the drifter:

$$
\frac{1}{2} \rho_{w} A_{w} C_{w}\langle|\mathbf{S}(z)| \mathbf{S}(z)\rangle=\frac{1}{2} \rho_{a} A_{a} C_{a}\left|\mathbf{W}-\mathbf{U}_{D}\right|\left(\mathbf{W}-\mathbf{U}_{D}\right),
$$

where $\mathbf{W}$ is the surface wind velocity vector, $\rho_{w}$ and $\rho_{a}$ are the water and air densities, $A_{w}$ and $A_{a}$ are the effective areas exposed to water and air, and $C_{w}$ and $C_{a}$ are the 
respective drags. The symbol \langle\rangle$=(1 / Z) \int d z$ represents the vertical average over the drifter vertical length $Z$. If the drifter motion can be assumed negligible with respect to the wind speed, (2) becomes

$$
\frac{1}{2} \rho_{w} A_{w} C_{w}\langle|\mathbf{S}(z)| \mathbf{S}(z)\rangle=\frac{1}{2} \rho_{a} A_{a} C_{a}|\mathbf{W}| \mathbf{W} .
$$

Projecting this equation in the downwind and crosswind (by definition to the right of the wind) directions and using the definition of drag area ratio $\left(R=A_{w} C_{w} / A_{a} C_{a}\right)$ we obtain

$$
\left\langle|\mathbf{S}| S_{\text {downwind }}\right\rangle=\left(\rho_{a} / R \rho_{w}\right) W^{2},
$$

and

$$
\left\langle|\mathbf{S}| S_{\text {crosswind }}\right\rangle=0,
$$

where $W$ is the wind speed.

Equations (4) and (5) are complicated due to the existence of vertical shear of horizontal currents near the surface, the veering of the currents with depth, and because they are intrinsically nonlinear.

As described in the next section, direct measurements of relative flow around the CODE drifters were made near its top and bottom extremities. From these measurements, we can define the proxy slip as follows:

$$
\left.\{\mathbf{S}\}=-\frac{1}{2} \text { (relative flow top }+ \text { relative flow bottom }\right) .
$$

Note that for weak Ekman and Stokes drift currents, which both decrease exponentially with depth, we can assume that relative flows vary linearly with depth across the drifter. In this case, the proxy slip is identical to the mean of $\mathbf{S}(z)$ over the drifter vertical extension. In the same way, the vertical shear of horizontal currents across the drogue is defined as

$\{\mathbf{S H}\}=$ relative flow top - relative flow bottom

Following Niiler et al. $(1987,1995)$ and Ralph and Niiler (1999) the following simple regression models, inspired from (4), can be used to relate drifter slippage to wind speed in the downwind direction:

$$
\{S\}_{\text {downwind }}=a / R W,
$$

and

$$
|\{\mathbf{S}\}|\{S\}_{\text {downwind }}=b / R W^{2},
$$

where $a$ and $b$ are unknown constants. Niiler et al. (1995) also included the shear in their regression model. In our

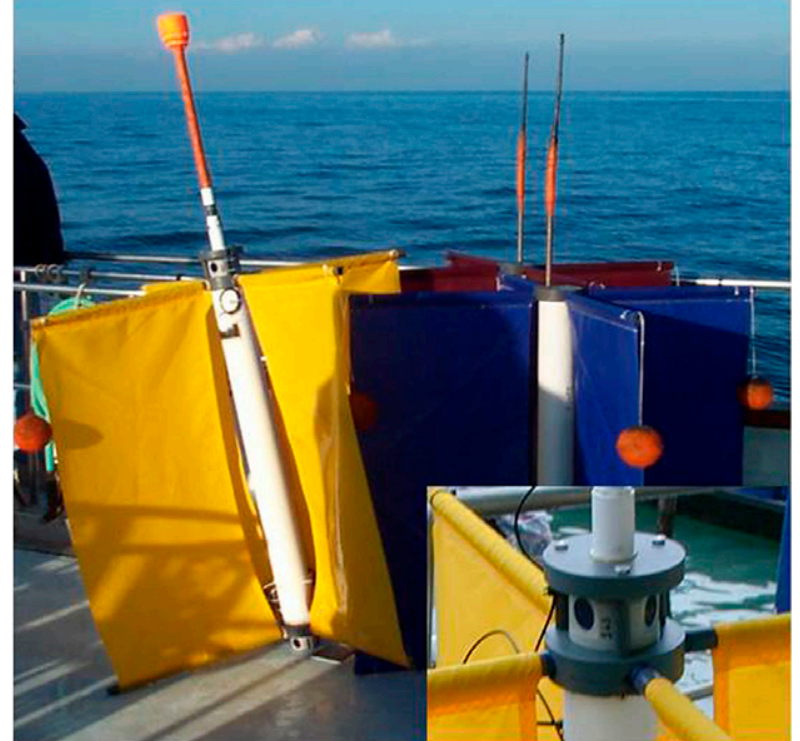

FIG. 1. (left) Prototype and (right) standard CODE drifters. The two Aquadopp velocimeters mounted at the top and bottom of the prototype drifter are clearly seen. The inset is an enlarged photograph of an Aquadopp velocimeter with transducers.

study, however, the inclusion of the shear did not yield significant and useful results (mostly likely due to large variability not related to the wind) and only the model with wind speed is considered in this paper for the sake of simplicity.

\section{Data and methods}

\section{a. The CODE drifter equipped with velocimeters}

The CODE drifter design used in this study was manufactured by Technocean and Data Buoy Instrumentation (DBI; model Argodrifter; https://www. facebook.com/DBiLLC). It was fitted with Nortek Aquadopp acoustic velocimeters (www.nortekusa.com) and Motorola GPS receivers to measure the horizontal relative flow around and below the drifters and their positions, respectively. The integration of these instruments was made without significantly changing the hydrodynamical characteristics (e.g., size, buoyancy, and drag area) of the drifters. However, the prototype drifter has a larger weight compared to the regular CODE due to the Aquadopps and batteries (10 vs $8.2-8.6 \mathrm{~kg}$ ). A photograph of the standard CODE drifters and the drifter fitted with velocimeters is depicted in Fig. 1. The nominal depth below the sea surface of the top and bottom velocimeters are 0.27 and $1.27 \mathrm{~m}$, respectively. The ratio of the drag areas of the submerged elements and the in-air parts $(R)$ is about 60 for both CODE with and without velocimeters. This value is larger than for 
the SVP design (40). The CODE drifter with velocimeters is referred to as the CODE prototype drifter. A schematic representation of this drifter, including dimensions, is shown in Fig. 2.

The Aquadopp velocimeters measure the relative water flow near the tubular body of the drifter with an accuracy of about $1 \mathrm{~cm} \mathrm{~s}^{-1}$ and with sampling frequency as large as $1 \mathrm{~Hz}$. They use the Doppler effect to measure current velocity by transmitting a short pulse of sound, listening to its echo, and measuring the change in frequency. These measurements are made with three custom-made transducer heads pointing in directions separated by $120^{\circ}$ and perpendicular to the main body of the drifter. Acoustic signals (at $2 \mathrm{MHz}$ ) in beams of $1.7^{\circ}$ width emitted by the three transducers are reflected by particles suspended in the water in the measurement cell centered at $1.1 \mathrm{~m}$ from the transducer head (the measurement cell is $1.5 \mathrm{~m}$ long and shaped like a triangle). The radial velocities obtained from each beam are combined by the Aquadopp software to produce the two components of the relative flow velocity perpendicular to the drifter. The Aquadopp velocimeters include ancillary sensors such as a tilt meter to measure its pitch and roll, a compass to record its orientation, a pressure sensor to measure the depth of the instrument, and a thermistor to measure sea surface temperature. The GPS receivers provided high-accuracy $(\sim 1 \mathrm{~m})$ position data at $1 \mathrm{~Hz}$. All the data were recorded on a datalogger and memory board inside the drifter.

\section{b. Direct measurements of flow relative to the CODE drifter}

CODE prototype drifters fitted with Aquadopp instruments were deployed for periods ranging from $\sim 20 \mathrm{~min}$ to about $10 \mathrm{~h}$ in various geographical locations, under a variety of wind and sea conditions (Table 1). Local wind and surface wave conditions were obtained from measurements made with research vessels, fixed platforms, and buoys near the CODE prototype drifters.

\section{1) MONTEREY BAY EXPERIMENTS}

The first deployments were carried out in Monterey Bay in the northeast Pacific Ocean on 5, 6, 8, 11, and 12 December 2000 with R/V Martin of the Moss Landing Marine Laboratories. The CODE prototype drifter was deployed for as long as $\sim 5 \mathrm{~h}$ and moved to the east or north with typical speeds of $20-40 \mathrm{~cm} \mathrm{~s}^{-1}$. Wind data at a nominal height of $7.2 \mathrm{~m}$ above mean sea level were collected at 2-min intervals on R/V Martin. Surface wave data were obtained from a Datawell Waverider buoy maintained by the Naval Postgraduate School in Monterey Bay with 30-min sampling period.

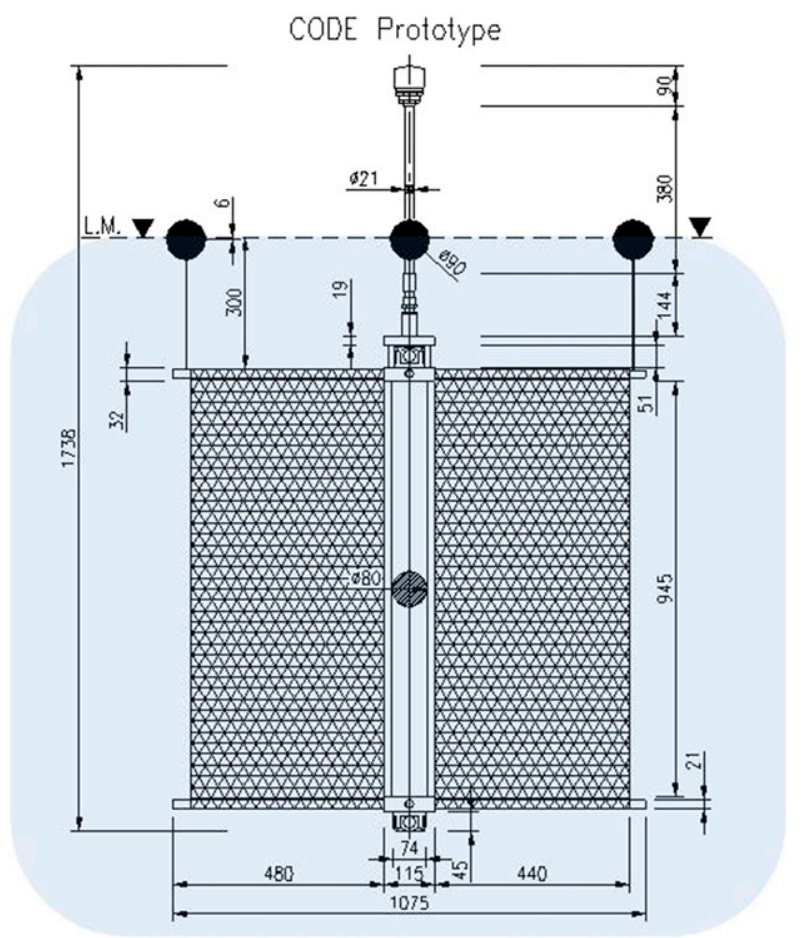

FIG. 2. Schematic diagram of the CODE prototype drifter. Dimensions are in millimeters. Submerged parts are shown in a shade of light gray.

Winds were low to moderate (vector averaged over $10 \mathrm{~min},<8 \mathrm{~m} \mathrm{~s}^{-1}$ ) and predominantly easterly in the morning, turning to westerly in the afternoon. The sea state was dominated by a swell coming from the NW, with peak period $(\mathrm{Tp})$ ranging between 10 and $15 \mathrm{~s}$ and significant wave height (Hs) of about $1 \mathrm{~m}$ on $5-11$ December 2000 , increasing to $2.5 \mathrm{~m}$ for the last experiment on 12 December 2000.

\section{2) GRADO EXPERIMENTS}

The same prototype drifter was operated off Grado in the northeastern Adriatic Sea outside the Gulf of Trieste on 12, 14, and 20 March 2001 with R/V Mirto. A meteorological station was installed on the boat to measure wind speed and direction at about $7 \mathrm{~m}$ above mean sea level. The true wind data were available at 2-min intervals. Wave data were available from a nearby Datawell Waverider buoy maintained by the Istituto Nazionale di Oceanografia e di Geofisica Sperimentale (OGS). Wave data were sampled every hour. On 20 March 2001, the Aquadopp velocimeters were erroneously programmed to average the currents over $10 \mathrm{~min}$ instead of $1 \mathrm{~s}$.

Wind speed was low $\left(<1 \mathrm{~m} \mathrm{~s}^{-1}\right)$ and waves quite insignificant ( $\sim 0.1 \mathrm{~m}$ from the south) on the first day. On $14 \mathrm{March}$, the wind increased to reach $2 \mathrm{~m} \mathrm{~s}^{-1}$ shifting from north-northwest to south-southwest. The Hs 
TABLE 1. Locations, dates, durations, and ranges in wind speed, currents speed, wave height (Hs), and period (Tp) for all the experiments with the CODE prototype drifter.

\begin{tabular}{|c|c|c|c|c|c|c|}
\hline Location & Deployment date & Duration (h:min) & Wind $\left(\mathrm{m} \mathrm{s}^{-1}\right)$ & Currents $\left(\mathrm{cm} \mathrm{s}^{-1}\right)$ & Hs (m) & $\mathrm{Tp}(\mathrm{s})$ \\
\hline Monterey Bay & 5 Dec 2000 & $1: 58$ & $1.3-5.0$ & $20-30$ & $1.1-1.3$ & $10-12$ \\
\hline Monterey Bay & 6 Dec 2000 & $3: 19$ & $0.5-7.8$ & 40 & $1.0-1.2$ & $13-14$ \\
\hline Monterey Bay & 8 Dec 2000 & $4: 58$ & $0.5-4.5$ & 30 & $1.3-1.5$ & $12-13$ \\
\hline Monterey Bay & 11 Dec 2000 & $4: 49$ & $0.1-3.3$ & $20-30$ & $0.8-1.0$ & $10-12$ \\
\hline Monterey Bay & 12 Dec 2000 & $3: 50$ & $0.6-5.9$ & $30-40$ & $2.0-2.5$ & $13-15$ \\
\hline N. Adriatic (Grado) & 12 Mar 2001 & $3: 25$ & $0.1-1.0$ & $10-30$ & 0.1 & $5-6$ \\
\hline N. Adriatic (Grado) & 14 Mar 2001 & $0: 55$ & $0.1-1.9$ & 10 & $0.1-0.2$ & $5-6$ \\
\hline N. Adriatic (Grado) & 20 Mar 2001 & $3: 27$ & $1.7-3.7$ & 10 & $0.3-0.4$ & $3-4$ \\
\hline N. Adriatic (Venice) & $28 \operatorname{Mar} 2001$ & $1: 42$ & $2.7-3.5$ & $20-30$ & - & - \\
\hline N. Adriatic (Venice) & 29 Mar 2001 & $3: 03$ & $0.2-3.5$ & 20 & $0.4-0.5$ & 4 \\
\hline N. Adriatic (Venice) & 6 Nov 2001 & $2: 45$ & $0.3-3.7$ & 30 & - & - \\
\hline N. Adriatic (Venice) & 8 Nov 2001 & $4: 24$ & $0.5-4.4$ & 20 & 0.3 & 4 \\
\hline N. Adriatic (Venice) & 2 Apr 2002 & $0: 44$ & $1.7-2.5$ & $<10$ & 0.1 & 3 \\
\hline N. Adriatic (Venice) & 2 Apr 2002 & $0: 56$ & $1.7-2.5$ & $<10$ & 0.1 & 3 \\
\hline N. Adriatic (Venice) & 3 Apr 2002 & $6: 03$ & $1.2-5.9$ & $20-30$ & $0.1-0.3$ & 3 \\
\hline N. Adriatic (Venice) & 3 Apr 2002 & $6: 41$ & $1.2-5.9$ & $10-20$ & $0.1-0.3$ & 3 \\
\hline N. Adriatic (Venice) & 4 Apr 2002 & $7: 25$ & $6.4-14.9$ & $20-30$ & $0.5-1.4$ & $2-4$ \\
\hline N. Adriatic (Venice) & 5 Apr 2002 & $5: 10$ & $4.2-7.9$ & $10-20$ & $0.4-0.8$ & $2-4$ \\
\hline N. Adriatic (Alliance) & 28 Sep 2002 & $0: 20$ & $0.4-4.8$ & $10-20$ & - & - \\
\hline N. Adriatic (Alliance) & 1 Oct 2002 & $7: 52$ & $0.7-4.5$ & $20-40$ & - & - \\
\hline N. Adriatic (Alliance) & 3 Oct 2002 & $8: 42$ & $0.1-3.2$ & $10-20$ & - & - \\
\hline N. Adriatic (Alliance) & 5 Oct 2002 & $9: 40$ & $0.1-9.6$ & $10-30$ & - & - \\
\hline
\end{tabular}

increased to about $0.2 \mathrm{~m}$ with a swell from the south with Tp of 5-6s. On 20 March 20, the wind was as strong as $3.6 \mathrm{~m} \mathrm{~s}^{-1}$ from the north and north-northeast, and waves coming from the south-southeast reached $0.3 \mathrm{~m}$. Note that this location is influenced by the outflow of the Isonzo River, which can produce a strong stratification and strong shear in the top meter below the surface. The drifter moved to the southwest or northeast directions with speeds of $10-30 \mathrm{~cm} \mathrm{~s}^{-1}$.

\section{3) VENICE EXPERIMENTS}

Two CODE prototype drifters were deployed in the vicinity of the Italian Consiglio Nazionale delle Ricerche (CNR) Acqua Alta Tower (located about $16 \mathrm{~km}$ to the southeast of Venice Lido Island) in the northwestern Adriatic Sea on 28 and 29 March and 6 and 8 November 2001 and 2-5 April 2002. Deployment and recovery operations were carried onboard R/V Litus on which a meteorological station was mounted to collect wind data at about $7 \mathrm{~m}$ above mean sea level. The waves were directionally recorded by three pressure transducers located on three legs of the tower (Cavaleri 2000). Wave data were obtained at 3-h intervals. On 4-5 April 2002, weather conditions precluded operations with R/V Litus and one CODE prototype drifter attached with a long line was deployed several times from the tower to collect data over short intervals (5-14 min). The line, which was kept loose while the drifter moved away, was used to fetch it back. The data of the first period with the line loose were only considered here (practically half of the deployment period, that is, as little as $2.5 \mathrm{~min}$ ). These data might be affected by the drag on the line, and possibly the wake of the tower, and therefore are less accurate. Nevertheless we considered them in this work because they correspond to the only cases with strong winds $\left(>10 \mathrm{~m} \mathrm{~s}^{-1}\right)$.

On 28-29 March 2001, winds were moderate $\left(<3.6 \mathrm{~m} \mathrm{~s}^{-1}\right)$ from the southeast on 28 March and northeast on 29 March. On 6-8 November 2001, wind speed varied at $0.3-4.4 \mathrm{~m} \mathrm{~s}^{-1}$ and wind direction was from the southeast (on 6 November) and southwest (on 8 November). On 29 March, there was some swell with Hs reaching $0.5 \mathrm{~m}$, Tp of $4 \mathrm{~s}$, coming from the southeast. On 8 November 2001, waves had an Hs near $0.3 \mathrm{~m}$, a Tp of about $4 \mathrm{~s}$, coming again from the southeast. No wave data were available on 28 March and 6 November. The drifters moved to the southwest or northwest with speeds of $20-30 \mathrm{~cm} \mathrm{~s}^{-1}$.

On 2-5 April 2002, winds were stronger, reaching a maximum on the morning of 4 April with speeds of $\sim 15 \mathrm{~m} \mathrm{~s}^{-1}$ and northeast direction (bora). Strong winds were associated with waves of $\mathrm{Hs}$ reaching $1.4 \mathrm{~m}$, with $\mathrm{Tp} \sim 3 \mathrm{~s}$, coming from the east. The drifters moved with typical speeds of $10-30 \mathrm{~cm} \mathrm{~s}^{-1}$ mainly toward the west.

\section{4) NORTHERN ADRIATIC EXPERIMENTS}

The last experiments with one CODE prototype drifter were carried onboard NATO R/V Alliance in several places in the northern Adriatic during the ADRIA02 

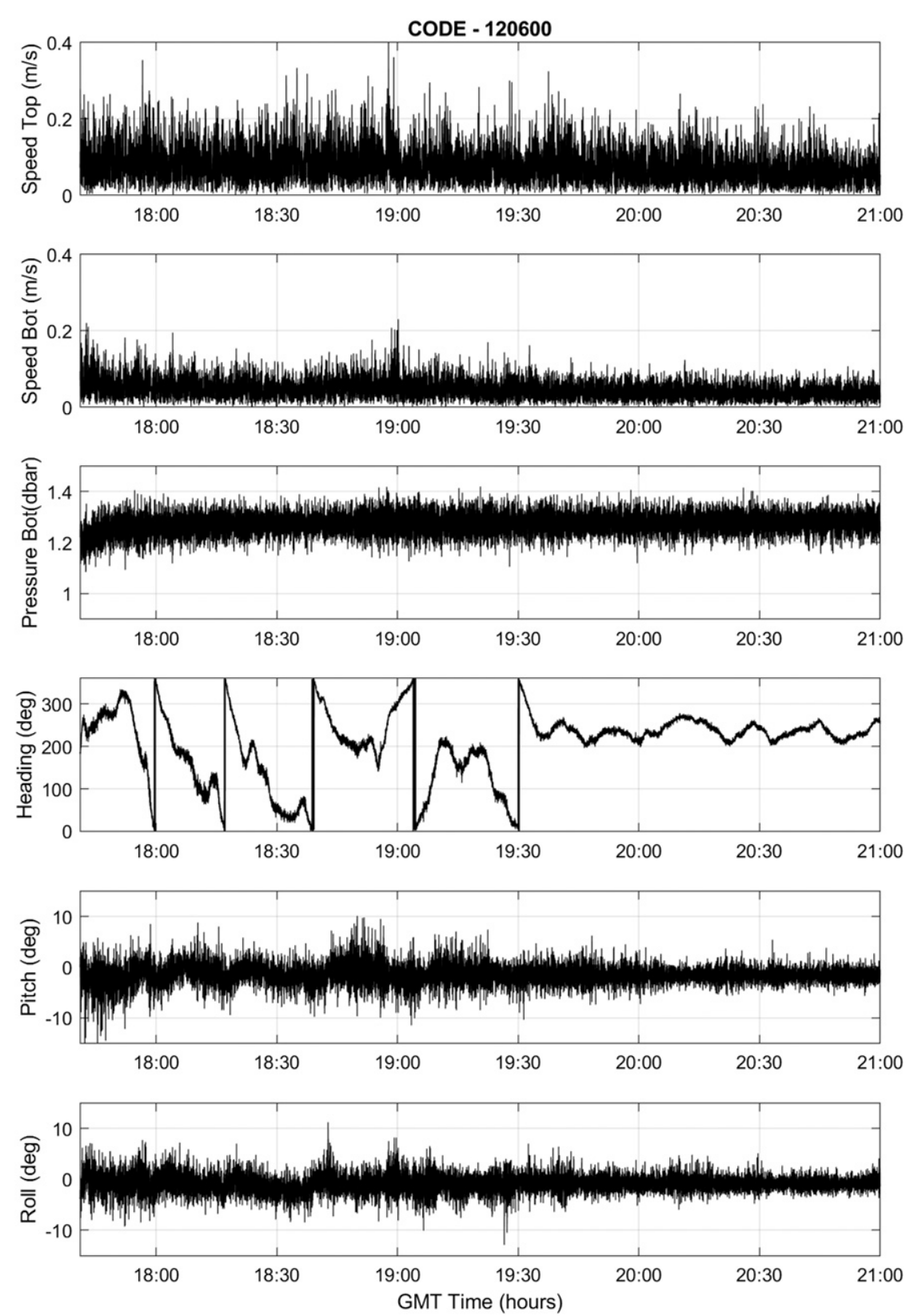

FIG. 3. Unfiltered data of relative speed, pressure, heading, pitch, and roll for the CODE prototype drifter deployed in Monterey Bay on 6 Dec 2000.

cruise (Boldrin et al. 2009) on 28 September and 1, 3, and 5 October 2002. Wind data at about $10 \mathrm{~m}$ above mean sea level were obtained at 5-min intervals. Wind speeds were in the range $0-5 \mathrm{~m} \mathrm{~s}^{-1}$. Sea state (waves) conditions were not recorded. The drifter moved with speeds of $10-40 \mathrm{~cm} \mathrm{~s}^{-1}$ in several directions (northwest, northeast, southeast).

\section{c. Drifter data processing}

The Aquadopp relative currents were projected horizontally using the tilt meter data and were converted to the zonal and meridional components using the compass information. The horizontal relative flow data were vector averaged using $50 \%$ overlapping 10 -min windows and sampled at 5-min intervals. For the experiments of 4-5 April 2002, the time windows were reduced to as little as $2.5 \mathrm{~min}$ because of the repeated short deployments with a rope. The pressure measured by the Aquadopp was corrected for a mean offset of less than $1 \mathrm{dbar}$. The measured wind speed was converted to the neutral wind speed at $10-\mathrm{m}$ height using a power law 

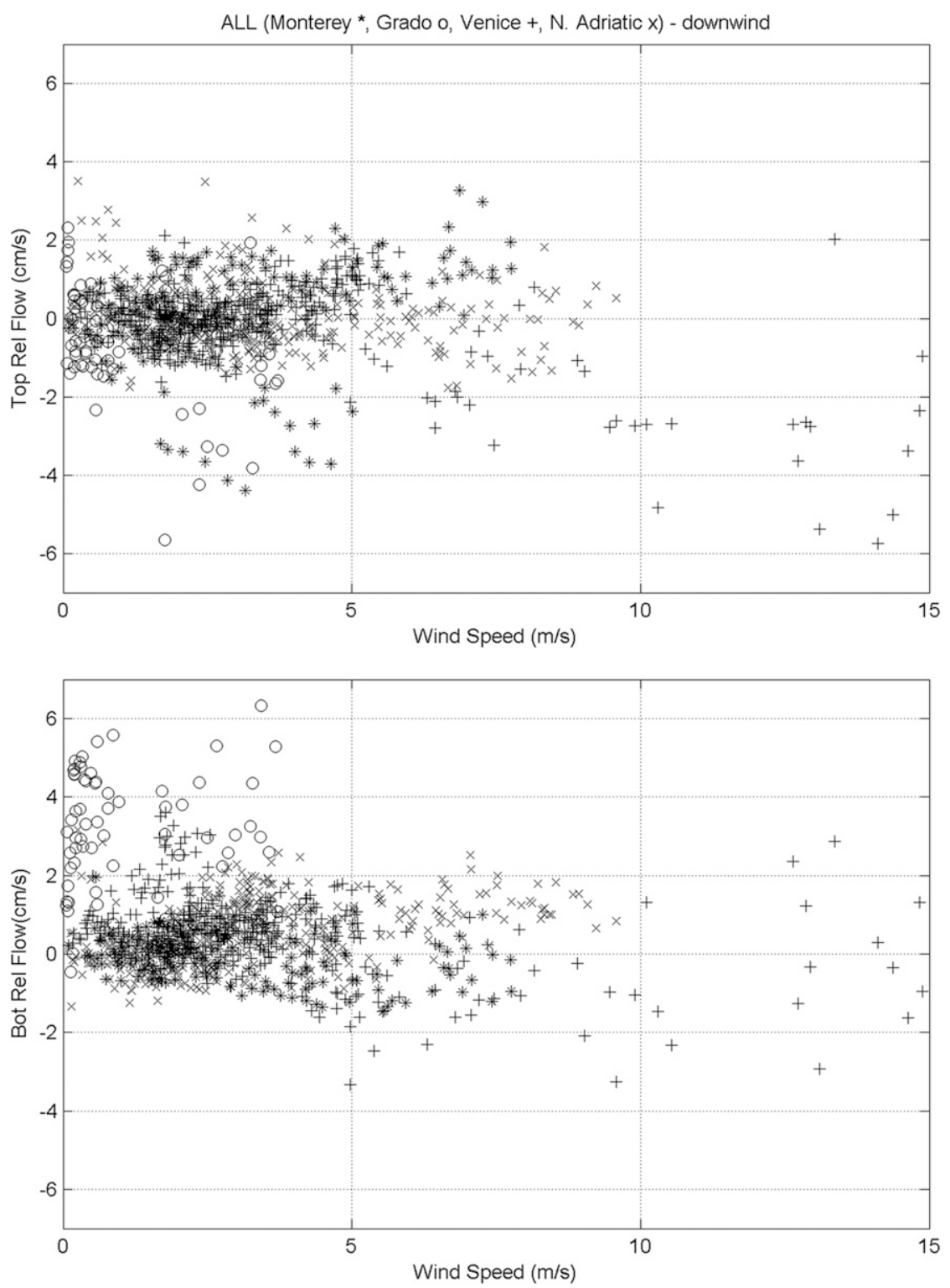

FIG. 4. Relative velocity components in the downwind direction measured by the top and bottom Aquadopp velocimeters: Monterey (*), Grado (o), Venice (+), and northern Adriatic (x). Velocities were averaged over 2.5-10-min intervals.

with exponent equal to $1 / 7$. The converted wind data were vector averaged in the same way as the Aquadopp measurements. The low-pass filtered relative flow data were subsequently projected in the down- and crosswind (positive to the right) directions.

\section{Results}

\section{a. High-frequency motion}

Figure 3 shows an example of the unfiltered data measured by the Aquadopp velocimeters mounted on the CODE drifter prototype deployed in Monterey Bay on 6 December 2000. The high-frequency motion of the drifter induced by the waves is evident in all the parameters displayed, especially for the top velocimeter, which measured speeds reaching a maximum of about $50 \mathrm{~cm} \mathrm{~s}^{-1}$, with a mean of $8 \mathrm{~cm} \mathrm{~s}^{-1}$ and standard deviation of $5 \mathrm{~cm} \mathrm{~s}^{-1}$. For the bottom velocimeter, the maximal speed is only about $20 \mathrm{~cm} \mathrm{~s}^{-1}$, and the mean and standard deviation are reduced to 5 and $3 \mathrm{~cm} \mathrm{~s}^{-1}$, respectively. The level of the bottom velocimeter shows fluctuations bounded by \pm 0.15 dbar corresponding to 

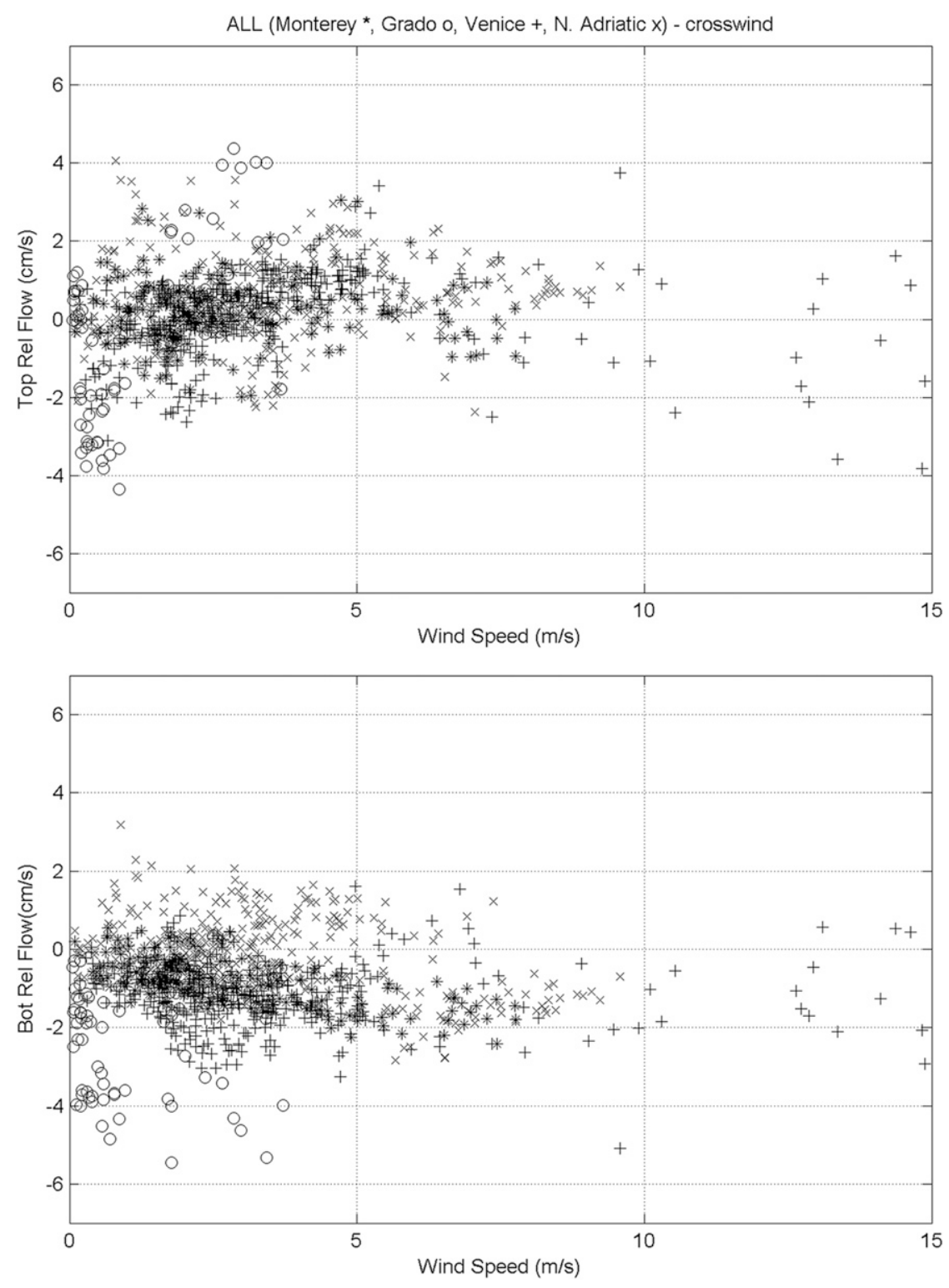

FIG. 5. As in Fig. 4, but for the crosswind direction. The crosswind component is positive to the right of the wind.

the heave motion. The pressure has a mean of 1.3 dbar with a standard deviation of $0.04 \mathrm{dbar}$, The drifter inclination (pitch and roll) is bounded by $15^{\circ}$, but the standard deviation is only about $2^{\circ}$. The compass data (heading) show that the drifter is slowly turning on itself initially with a period of about $20 \mathrm{~min}$, but stabilizes after 1930 UTC.

\section{b. Low-frequency relative flow}

The low-pass filtered downwind and crosswind components of velocity measured by the top and bottom velocimeters are displayed in Figs. 4 and 5 for all the 22 experiments in Monterey Bay and the northern Adriatic Sea. The low-frequency relative flow components can be as large as $\sim 6 \mathrm{~cm} \mathrm{~s}^{-1}$, even under weak winds for the Grado experiments. Visual inspection of Fig. 4 reveals that the top (bottom) relative flow tends to decrease (increase) in the downwind direction, with increasing wind speed. Excluding the Grado experiments, the relative flow components are essentially bounded by $2 \mathrm{~cm} \mathrm{~s}^{-1}$ for wind speed less than $10 \mathrm{~m} \mathrm{~s}^{-1}$ and they are typically an order of magnitude smaller than the drifter speeds (see Table 1).

\section{c. Proxy slip and shear}

The proxy slip and shear, defined in (6) and (7) and derived from the top and bottom Aquadopp velocimeter data averaged over $2.5-10$-min intervals, were projected 

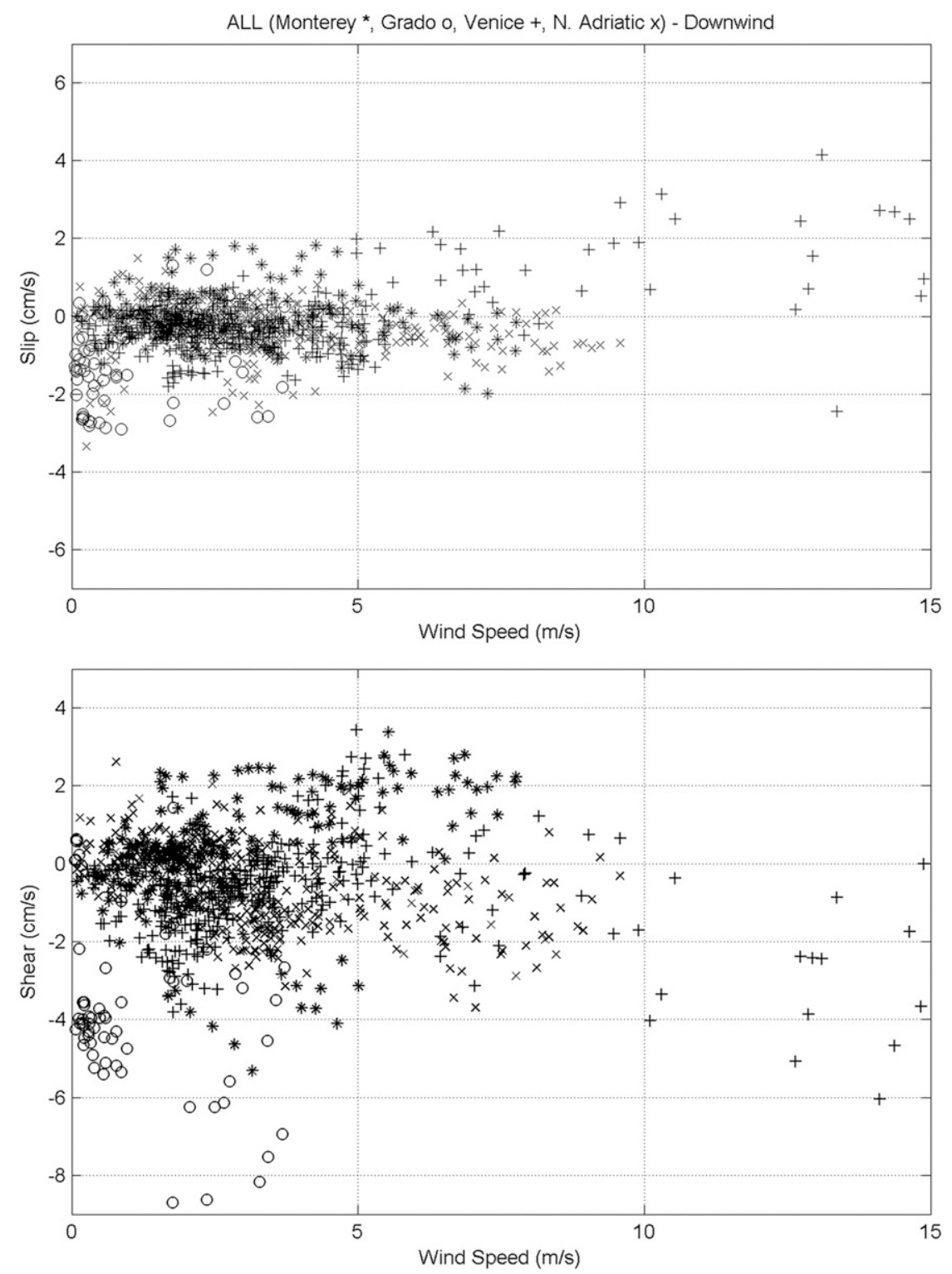

FIG. 6. Proxy slip and shear in the downwind direction derived from the top and bottom Aquadopp velocimeter data averaged over 2.5-10-min intervals: Monterey (*), Grado (o), Venice (+), and northern Adriatic (x).

in the down- and crosswind directions (Figs. 6 and 7). Slips can be larger than $4 \mathrm{~cm} \mathrm{~s}^{-1}$ in the downwind direction for wind speeds of $10-15 \mathrm{~m} \mathrm{~s}^{-1}$. For smaller wind speeds, they are essentially bounded by $\pm 3 \mathrm{~cm} \mathrm{~s}^{-1}$. In the crosswind direction, they are bounded by $\pm 3 \mathrm{~cm} \mathrm{~s}^{-1}$, except for some values of the Grado experiments reaching $\sim 4 \mathrm{~cm} \mathrm{~s}^{-1}$. Visual inspection reveals a general increase of the downwind slip with increasing wind speed. In contrast for the crosswind direction there is no apparent trend.

Shear components are generally larger than the slips with values in excess of $9 \mathrm{~cm} \mathrm{~s}^{-1}$ in the upwind (Fig. 6) and crosswind (to the right of the wind; Fig. 7) directions.
In the downwind direction, the shears tend to become more negative for large wind speeds. The Grado experiments are characterized by large shears in upwind and crosswind directions, under weak wind conditions. In absolute values, the shear can reach $12 \mathrm{~cm} \mathrm{~s}^{-1}$ (not shown).

\section{d. Drifter slippage versus wind speed}

To seek relationships similar to (8) and (9), we averaged the proxy slips in $0.5 \mathrm{~m} \mathrm{~s}^{-1}$ wind speed intervals and calculated regression lines forced through the origin. For the downwind slip versus wind speed (Fig. 8, top) the slope of the regression line is $a / R=0.08 \pm 0.04$. 

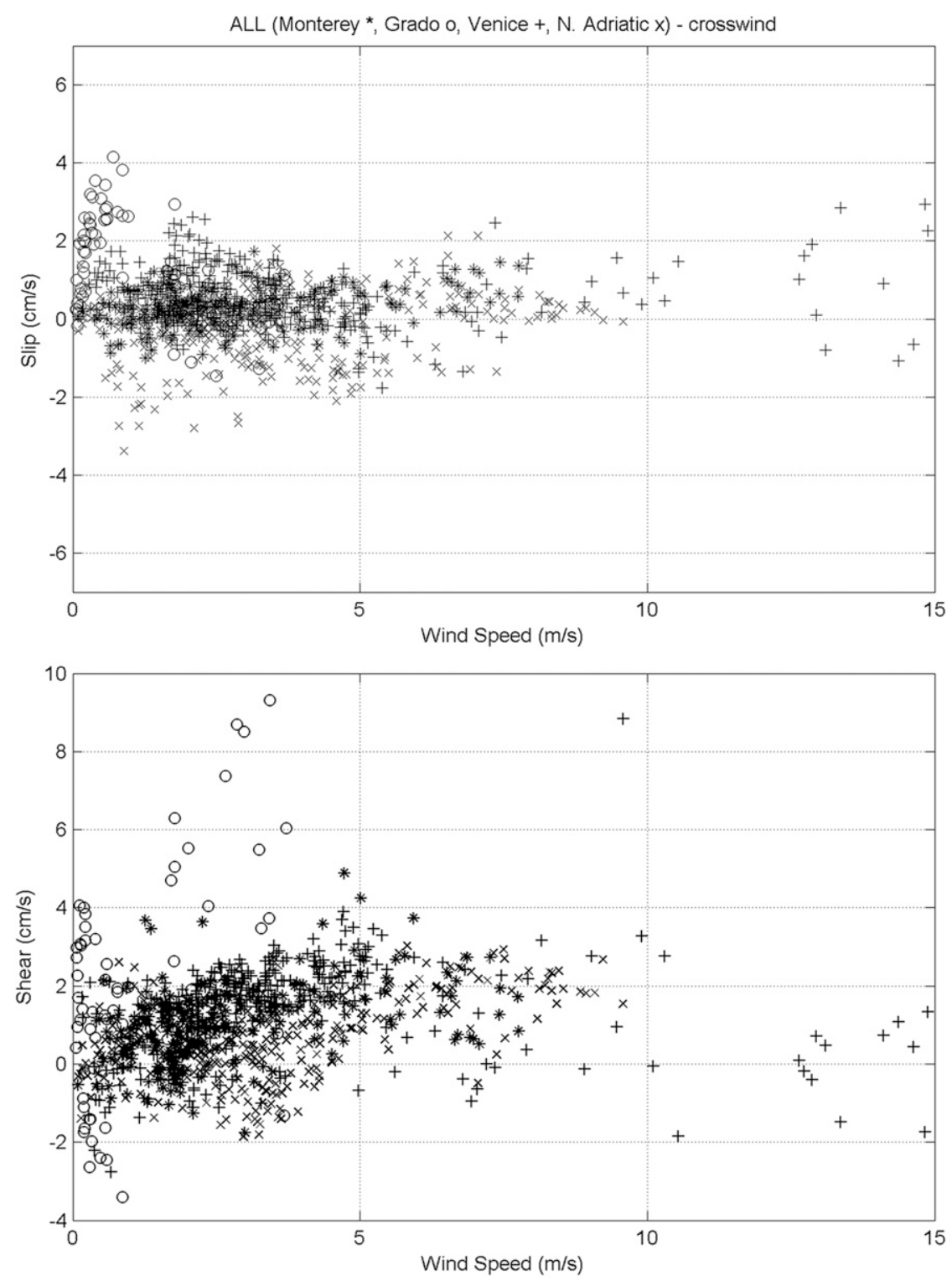

FIG. 7. As in Fig. 6, but for the crosswind direction. The crosswind component is positive to the right of the wind.

The coefficient of determination is $46 \%$. If we consider the product of the slip speed times its downwind component and plot it versus the square of the wind speed (Fig. 8, bottom), the slope of the regression line is $b / R=0.02 \pm 0.01$ (coefficient of determination of $33 \%$ ). Thus, both regressions support the conclusion that the drifter slip is downwind and amounts to about $0.1 \%$ of the wind speed.

\section{Discussion and conclusions}

Direct measurements of relative flow near the top and bottom of CODE drifters were made in various geographical and wind conditions to assess the waterfollowing capabilities of these quasi-Lagrangian instruments. The observations were obtained in Monterey Bay and in the northern Adriatic Sea in winds as large as $15 \mathrm{~m} \mathrm{~s}^{-1}$ and waves up to $2-3 \mathrm{~m}$. The relative flow measurements and wind data were low-pass filtered, and the down- and crosswind components of relative flow, proxy slip, and shear were calculated. Relative flow was as large as $\sim 6 \mathrm{~cm} \mathrm{~s}^{-1}$ in the downwind direction (Fig. 4). The downwind slip was bounded by $4 \mathrm{~cm} \mathrm{~s}^{-1}$ in absolute value, with a tendency to increase with increasing wind speed. Excluding the measurements made off Grado in the vicinity of a river outflow, 

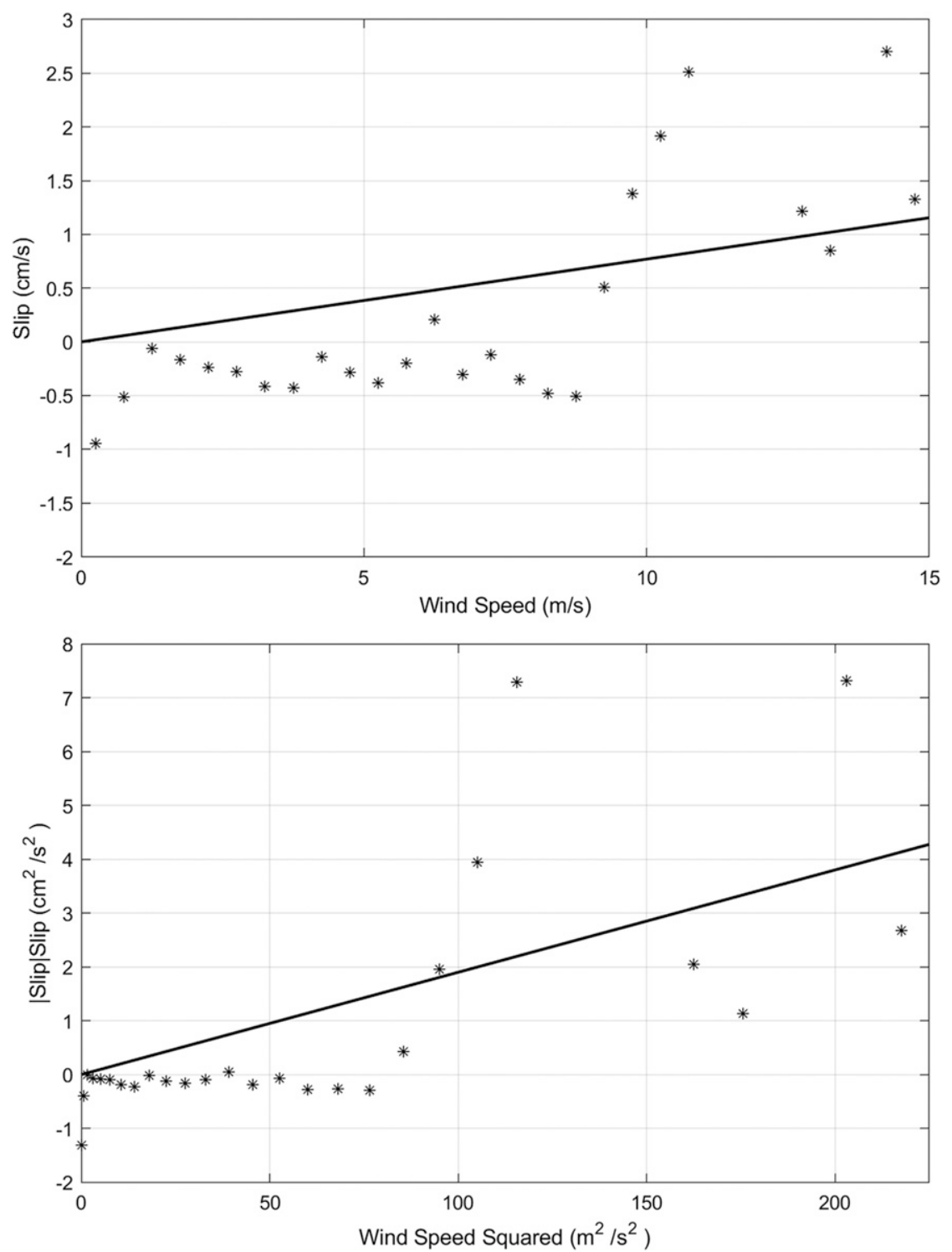

FIG. 8. (top) Proxy slip in the downwind direction $\{S\}_{\text {downwind }}$ averaged in $0.5 \mathrm{~m} \mathrm{~s}^{-1}$ wind speed intervals vs wind speed $W$. (bottom) The quantity $|\{\mathbf{S}\}|\{S\}_{\text {downwind }}$ vs $W^{2}$, where the mean slip and the wind speed have been averaged in $0.5 \mathrm{~m} \mathrm{~s}^{-1}$ wind speed intervals. The solid lines represent the linear regression lines forced through the origin.

the downwind shear was bounded by $6 \mathrm{~cm} \mathrm{~s}^{-1}$ with a tendency to decrease with wind speed. In the crosswind direction, there was no apparent trend with wind speed for the slip and shear (Fig. 7). Regression lines inspired by (8) and (9) were calculated after further averaging in $0.5 \mathrm{~m} \mathrm{~s}^{-1}$ wind speed intervals. The results support the main conclusion that the slip is essentially downwind and increases with wind speed with a slope of $0.1 \%$. Quantitative analysis of the effect of waves of the CODE water-following capabilities was not performed due to the small range of $\mathrm{Hs}$, the missing data for some experiments, and because waves were generally highly correlated with the local wind forcing. Likewise, the shear across the drifter was not included in the regression model since its addition did not result in significant conclusions. Despite the relatively large values $\left(6-10 \mathrm{~cm} \mathrm{~s}^{-1}\right)$ for the measured relative flow, proxy slip, and shear averaged over $2.5-10 \mathrm{~min}$, we can conclude that the CODE drifter is a good Lagrangian drifter, which follows the near-surface currents (about $0.5 \mathrm{~m}$ below the sea surface) with downwind slip of about $0.1 \%$ of the wind speed in wind (and related 
local wind-generated waves) conditions ranging over $0-15 \mathrm{~m} \mathrm{~s}^{-1}$. This confirms, and expands, the original results of Davis (1985) and the linear regression could be used to correct past and future near-surface current measurements with CODE drifters using wind measurements or products.

The downwind slip of the CODE drifter is similar to the value obtained for the SVP drifter with a drogue attached at $15 \mathrm{~m}$ depth (Niiler et al. 1995) so these two standard drifters measure the near-surface currents with about the same accuracy, but obviously at different depths. It is interesting to note that the drifter slip is an order of magnitude smaller than the wind-driven currents $($ Ekman + slip + Stokes $)$ estimated for CODE drifters in the Mediterranean (Poulain et al. 2009), which are about $1 \%$ of the wind speed. The CARTHE drifter appears to have slightly better accuracy (slippage of $0.5 \%$ of wind speed; Novelli et al. 2017) but relative currents around this new drifter design have not been measured directly yet.

As demonstrated in this paper, drifters fitted with acoustic velocimeters (or profilers) are effective Lagrangian instruments to measure currents and shear close to the sea surface. Hence, they can be combined with other mobile (e.g., gliders) or fixed platforms (e.g., moorings) to explore the dynamics at the airsea interface. These measurements are crucial to study air-sea interaction processes and, in particular, to improve the parameterization of the wind stress flux in numerical models of ocean circulation. Measuring the relative flow with acoustic velocimeters is essential in order to accurately measure the horizontal and vertical structure of the near-surface currents with a large number of low-cost drifters, as part of specific scientific studies and for operational uses such as oil spill mitigation and search-and-rescue operations.

Acknowledgments. We thank all the individuals who have been involved with the CODE prototype drifter experiments, including Michele Deponte, Davide Deponte, Fabio Brunetti, Paolo Mansutti of OGS, Pietro Zanasca of NURC, and Andy Sybrandy of Pacific Gyre, Inc. (www.pacificgyre.com). Laura Ursella and Thomas Miraglio helped with some of the data processing. Luigi Cavaleri and Luciana Bertotti of CNR/ISMAR organized the logistics to use the Acqua Alta Tower and provided wave and wind data from the tower. We are grateful to the anonymous reviewers for providing constructive comments on the initial manuscript. Thanks to Peter Niiler for exciting discussions about drifter slippage issues over the last couple of decades. They were the inspiration and motivation for this work.

\section{REFERENCES}

Boldrin, A., S. Carniel, M. Giani, M. Marini, F. Bernardi Aubry, A. Campanelli, F. Grilli, and A. Russo, 2009: Effects of bora wind on physical and biogeochemical properties of stratified waters in the northern Adriatic. J. Geophys. Res., 114, C08S92, https://doi.org/10.1029/2008JC004837.

Breivik, Ø., A. A. Allen, C. Maisondieu, and M. Olagnon, 2013: Advances in search and rescue at sea. Ocean Dyn., 63, 83-88, https://doi.org/10.1007/s10236-012-0581-1.

_ - P. A. E. M. Janssen, and J.-R. Bidlot, 2014: Approximate Stokes drift profiles in deep water. J. Phys. Oceanogr., 44, 2433-2445, https://doi.org/10.1175/JPO-D-14-0020.1.

—, J.-R. Bidlot, and P. A. E. M. Janssen, 2016: A Stokes drift approximation based on the Phillips spectrum. Ocean Modell., 100, 49-56, https://doi.org/10.1016/j.ocemod.2016.01.005.

Cavaleri, L., 2000: The oceanographic tower Acqua Alta-Activity and prediction of sea states at Venice. Coastal Eng., 39, 29-70, https://doi.org/10.1016/S0378-3839(99)00053-8.

Centurioni, L., A. Hornayi, C. Cardinali, E. Charpentier, and R. Lumpkin, 2017: A global ocean observing system for measuring sea level atmospheric pressure: Effects and impacts on numerical weather prediction. Bull. Amer. Meteor. Soc., 98 , 231-238, https://doi.org/10.1175/BAMS-D-15-00080.1.

Chereskin, T. K., P. P. Niiler, and P.-M. Poulain, 1989: A numerical study of the effect of upper ocean shear on flexible drogued drifters. J. Atmos. Oceanic Technol., 6, 243-253, https://doi.org/ 10.1175/1520-0426(1989)006<0243:ANSOTE > 2.0.CO;2.

Clarke, A. J., and S. Van Gorder, 2018: The relationship of nearsurface float, Stokes drift and the wind stress. J. Geophys. Res. Oceans, 123, 4680-4692, https://doi.org/10.1029/2018JC014102.

Davis, R. E., 1985: Drifter observation of coastal currents during CODE: The method and descriptive view. J. Geophys. Res., 90, 4741-4655, https://doi.org/10.1029/JC090iC03p04741.

Ekman, V. W., 1905: On the influence of the Earth's rotation on ocean currents. Ark. Mat. Astron. Fys., 2 (11), 1-52.

Geyer, W. R., 1989: Field calibration of mixed-layer drifters. J. Atmos. Oceanic Technol., 6, 333-342, https://doi.org/10.1175/ 1520-0426(1989)006<0333:FCOMLD >2.0.CO;2.

Kalampokis, A., M. Uttieri, P.-M. Poulain, and E. Zambianchi, 2016: Validation of HF radar-derived currents in the Gulf of Naples with Lagrangian data. IEEE Geosci. Remote Sens. Lett., 13, 1452-1456, https://doi.org/10.1109/LGRS.2016.2591258.

Kirwan, A. D., Jr., G. McNally, M.-S. Chang, and R. Molinari, 1975: The effect of wind and surface currents on drifters. J. Phys. Oceanogr., 5, 361-368, https://doi.org/10.1175/15200485(1975)005<0361:TEOWAS $>2.0$. CO; 2 .

Lumpkin, R., and M. Pazos, 2007: Measuring surface currents with SVP drifters: The instrument, its data and some results. Lagrangian Analysis and Prediction of Coastal and Ocean Dynamics, A. Griffa et al., Eds., Cambridge University Press, 39-67.

— , and G. C. Johnson, 2013: Global ocean surface velocities from drifters: Mean, variance, El Niño-Southern Oscillation response, and seasonal cycle. J. Geophys. Res. Oceans, 118 , 2992-3006, https://doi.org/10.1002/jgrc.20210.

—, T. Özgökmen, and L. Centurioni, 2017: Advances in the application of surface drifters. Annu. Rev. Mar. Sci., 9, 59-81, https://doi.org/10.1146/annurev-marine-010816-060641.

Lund, B., and Coauthors, 2018: Near-surface current mapping by shipboard marine X-band radar: A validation. J. Atmos. Oceanic Technol., 35, 1077-1090, https://doi.org/10.1175/JTECH-D17-0154.1. 
Mackas, D. L., W. R. Crawford, and P. P. Niiler, 1989: A performance comparison for two Lagrangian drifter designs. Atmos.-Ocean, 27, 443-456, https://doi.org/10.1080/07055900.1989.9649346.

Maximenko, N. A., R. Lumpkin, and L. Centurioni, 2013: Ocean surface circulation. Ocean Circulation and Climate, G. Siedler et al. Eds., International Geophysics Series, Vol. 103, Academic Press, 283-304.

Molcard, A., P.-M. Poulain, P. Forget, A. Griffa, Y. Barbin, J. Gaggelli, J. C. De Maistre, and M. Rixen, 2009: Comparison between VHF radar observations and data from drifter clusters in the Gulf of La Spezia (Mediterranean Sea). J. Mar. Syst., 78 (Suppl. 1), S79-S89, https://doi.org/10.1016/j.jmarsys.2009.01.012.

Niiler, P. P., 2001: The World Ocean surface circulation. Ocean Circulation and Climate, G. Siedler et al., Eds., International Geophysics Series, Vol. 103, Academic Press, 193-204.

— , R. E. Davis, and H. J. White, 1987: Water-following characteristics of a mixed layer drifter. Deep-Sea Res., 34A, 18671881, https://doi.org/10.1016/0198-0149(87)90060-4.

— A. Sybrandy, K. Bi, P.-M. Poulain, and D. Bitterman, 1995: Measurements of the water-following capability of holey-sock and TRISTAR drifters. Deep-Sea Res., 42, 1951-1964, https:// doi.org/10.1016/0967-0637(95)00076-3.

Novelli, G., C. M. Guigand, C. Cousin, E. H. Ryan, N. J. Laxague, H. Dai, B. K. Haus, and T. M. Özgökmen, 2017: A biodegradable surface drifter for ocean sampling on a massive scale. J. Atmos. Oceanic Technol., 34, 2509-2532, https://doi.org/ 10.1175/JTECH-D-17-0055.1.

Ohlmann, J. C., and P. P. Niiler, 2005: Circulation over the continental shelf in the northern Gulf of Mexico. Prog. Oceanogr., 64, 45-81, https://doi.org/10.1016/j.pocean.2005.02.001.

_ P. White, L. Washburn, B. Emery, E. Terrill, and M. Otero, 2007: Interpretation of coastal HF radar-derived surface currents with high-resolution drifter data. J. Atmos. Oceanic Technol., 24, 666-680, https://doi.org/10.1175/JTECH1998.1.

Poulain, P.-M., 1999: Drifter observations of surface circulation in the Adriatic Sea between December 1994 and March 1996. J. Mar Syst., 20, 231-253, https://doi.org/10.1016/S0924-7963(98)00084-0.
2013: Tidal currents in the Adriatic as measured by surface drifters. J. Geophys. Res. Oceans, 118, 1434-1444, https://doi.org/ 10.1002/jgrc.20147.

— , and L. Centurioni, 2015: Direct measurements of World Ocean tidal currents with surface drifters. J. Geophys. Res. Oceans, 120, 6986-7003, https://doi.org/10.1002/2015JC010818.

—, R. Gerin, E. Mauri, and R. Pennel, 2009: Wind effects on drogued and undrogued drifters in the eastern Mediterranean. J. Atmos. Oceanic Technol., 26, 1144-1156, https://doi.org/ 10.1175/2008JTECHO618.1.

—, M. Menna, and E. Mauri, 2012: Surface geostrophic circulation of the Mediterranean Sea derived from drifter and satellite altimeter data. J. Phys. Oceanogr., 42, 973-990, https:// doi.org/10.1175/JPO-D-11-0159.1.

— A. Aussani, R. Gerin, R. Junwirth, E. Mauri, M. Menna, and G. Notarstefano, 2013: Mediterranean surface currents measured with drifters: From basin to subinertial scales. Oceanography, 26 (1), 38-47, https://doi.org/10.5670/oceanog.2013.03.

- M. Menna, and R. Gerin, 2018: Mapping Mediterranean tidal currents with surface drifters. Deep-Sea Res., 138, 22-33, https://doi.org/10.1016/j.dsr.2018.07.011.

Ralph, E. A., and P. P. Niiler, 1999: Wind-driven currents in the tropical Pacific. J. Phys. Oceanogr., 29, 2121-2129, https://doi.org/ 10.1175/1520-0485(1999)029<2121:WDCITT>2.0.CO;2.

Röhrs, J., and K. H. Christensen, 2015: Drift in the uppermost part of the ocean. Geophys. Res. Lett., 42, 10349-10356, https:// doi.org/10.1002/2015GL066733.

— - _ L. R. Hole, G. Broström, M. Drivdal, and S. Sundby, 2012: Observation-based evaluation of surface wave effects on currents and trajectory forecasts. Ocean Dyn., 62, 1519-1533, https://doi.org/10.1007/s10236-012-0576-y.

Stokes, G. G., 1847: On the theory of oscillatory waves. Trans. Cambridge Philos. Soc., 8, 441-455.

Thoppil, P. G., J. G. Richman, and P. J. Hogan, 2011: Energetics of a global ocean circulation model compared to observations. Geophys. Res. Lett., 38, L15607, https://doi.org/10.1029/ 2011 GL048347. 